\title{
REGIONAL AND INDUSTRY-SPECIFIC APPROACH TO THE FORMATION OF THE WATER MANAGEMENT COMPLEX DEVELOPMENT STRATEGY
}

\author{
Olga A. Chernova \\ Southern Federal University, Rostov-on-Don, Russian Federation; \\ Russian Information, Analytical and Scientific Research Water Management Center, \\ Rostov-on-Don, Russian Federation
}

\begin{abstract}
The level of the water management complex development affects the state of the resource potential of the region and its structural and sectoral features. The purpose of this article is to reveal the relations and interdependence of the processes of strategic development of the water management complex and regional economy; to form recommendations that contribute to the development of these relations. The problem of forming a strategy for the water management complex development is considered within the framework of the sustainable development concept, which takes socio-economic and environmental aspects into account. As a result of the study the influence of the water management complex on the socio-economic potential of the southern Russian regions was analyzed. Scenario variants of the water management complex development in the regions are identified, their typology is carried out. The necessity of forming a mechanism of interdepartmental coordination to improve the efficiency of the management system for the strategic development of the water management complex is justified. Conclusions are drawn about the need to supplement the basin approach to water resources management with a regional-sectoral approach. This will make it possible to link the development strategy of the water management complex with the sectoral structural changes in the region. The results of the study can be used by regional authorities and water resources management to solve the problems of increasing the sustainability of water and regional ecosystems.
\end{abstract}

Key words: regional economy, water management complex, water resources, sustainable development, development strategy.

Citation. Chernova O.A. Regional and Industry-Specific Approach to the Formation of the Water Management Complex Development Strategy. Vestnik Volgogradskogo gosudarstvennogo universiteta. Ekonomika [Journal of Volgograd State University. Economics], 2021, vol. 23, no. 3, pp. 38-50. (in Russian). DOI: https://doi.org/10.15688/ek.jvolsu.2021.3.4

\section{РЕГИОНАЛЬНО-ОТРАСЛЕВОЙ ПОДХОД К ФОРМИРОВАНИЮ СТРАТЕГИИ РАЗВИТИЯ ВОДОХОЗЯЙСТВЕННОГО КОМПЛЕКСА}

Аннотация. Уровень развития водохозяйственного комплекса во многом определяет состояние ресурсного потенциала региона и его структурно-отраслевые особенности. Однако в современных исследованиях вопросам обеспечения сопряженного развития региональной и водохозяйственной систем уделяется недостаточно внимания. Цель данной статьи состоит в раскрытии взаимосвязи и взаимообусловленности процессов стратегического развития водохозяйственного комплекса и регионального хозяйства, разработке рекомендаций, способствующих развитию данных взаимосвязей. Проблематика формирования стратегии раз- 
вития водохозяйственного комплекса рассматривается в рамках концепции устойчивого развития, учитывающей социально-экономические и экологические аспекты. В результате исследования был проведен анализ влияния водохозяйственного комплекса на социально-экономический потенциал южнороссийских регионов. Определены сценарные варианты развития водохозяйственного комплекса в регионах, проведена их типологизация. Обоснована необходимость формирования механизма межведомственной координации для повышения эффективности функционирования системы управления стратегическим развитием водохозяйственного комплекса. Сделаны выводы о необходимости дополнения бассейнового подхода к управлению водными ресурсами регионально-отраслевым подходом, что позволит увязать стратегию развития водохозяйственного комплекса с отраслевыми структурными преобразованиями в регионе. Результаты исследования могут быть использованы региональными властями и менеджментом водных ресурсов для решения задач повышения устойчивости развития водных и региональных экосистем.

Ключевые слова: региональная экономика, водохозяйственный комплекс, водные ресурсы, устойчивое развитие, стратегия развития.

Цитирование. Чернова О. А. Регионально-отраслевой подход к формированию стратегии развития водохозяйственного комплекса // Вестник Волгоградского государственного университета. Экономика. 2021. - T. 23, № 3. - C. 38-50. - DOI: https://doi.org/10.15688/ek.jvolsu.2021.3.4

\section{Введение}

Важнейшая роль в системе регионального хозяйства отводится водохозяйственному комплексу (ВХК), который поддерживает осуществление базовых функций жизнеообеспечения и реализацию хозяйственной деятельности. Уровень развития водохозяйственного комплекса во многом определяет состояние ресурсного потенциала региона и его структурно-отраслевые особенности. При этом в контексте тактического управления ВХК важное значение имеет текущее состояние водных ресурсов, а в стратегическом плане - возможности наращивания водного потенциала для достижения необходимого соответствия водных ресурсов региональным социально-экономическим потребностям. Достаточное и одновременно рациональное обеспечение водными ресурсами потребностей региональных субъектов способствует реализации планов, программ, проектов, поддерживающих стабильное функционирование региональной экономической системы.

Управленческие решения в рамках формирования стратегии развития ВХК могут существенно повлиять на процессы регионального развития. Однако в современных исследованиях проблематике обеспечения сопряженного развития региональной и водохозяйственной систем уделяется недостаточно внимания. В определенной степени причиной этому является используемый бассейновый подход к управлению водными ресурсами. Между тем ряд исследователей подчеркивают, что для обеспечения устойчивого развития водных ресурсов необходимо принятие согласованных совместных решений региональными и отраслевыми властями, включая межрегиональные согласования [Ahmadov, 2020; Achieve Sustainable Development ... , 2020; Tsani et al., 2020; Achieving ..., 2021]. Стратегия развития ВХК региона, основанная исключительно на данных о состоянии водной системы, может быть определена как «опора на сохранение статус-кво, продолжение устоявшейся практики» [Do Conservation ... , 2004]. Это может привести к неэффективным водохозяйственным решениям. Например, решение о строительстве гидроузла, приводящее к поднятию уровня воды, может иметь негативные эффекты в масштабах развития экономики региона: сокращение сельскохозяйственных угодий, ухудшение условий функционирования рыбных хозяйств, снижение рекреационного потенциала территории. В этой связи стоит упомянуть проект строительства Багаевского гидроузла в Ростовской области, в отношении которого до сих пор идет дискуссия о характере его влияния и возможных последствиях для региональной экономики.

Эти аспекты, отражающие важность исследования проблематики учета региональноотраслевых детерминант при формировании стратегии развития ВХК, стали основанием для написания данной статьи. Наша гипотеза заключается в том, что перспективным подходом к формированию стратегий управления развитием ВХК является регионально-отраслевой, который в дополнение к бассейновому 
позволит поддержать долгосрочные планы регионального социально-экономического развития. Цель статьи - раскрыть взаимосвязь и взаимообусловленность процессов стратегического развития ВХК и регионального хозяйства, разработать рекомендации, способствующие развитию данных взаимосвязей.

\section{Методология и методы исследования}

Важность водных экосистем для благополучия человека и необходимость согласования направлений их развития с экономическими целями отмечается в довольно большом числе исследований: [Integrated Planning ... , 2017; Development ..., 2008; Regionalization of Water ... , 2018; Tsani et al., 2020]. Проблематика сопряженного решения проблем развития водохозяйственных комплексов и хозяйственных систем регионов получила в современном научном дискурсе название «гидродипломатия». Как отмечают N. Nagabhatla, M. CassidyNeumiller, N. Francine, N. Maatta, участие всех заинтересованных сторон в принятии решений по использованию водных ресурсов имеет определяющее значение в понимании их последствий для экономики региона и социальной сферы [Water ..., 2021]. P. Dou, Sh. Zuo, Y. Ren, M. Rodriguez, Sh. Dai также подчеркивают, что решения в отношении использования водных ресурсов не могут быть использованы без увязки с решениями по управлению городской окружающей средой [Refined Water Security ..., 2021].

В целом можно сказать, что в зарубежных исследованиях последних лет подчеркивается важность водных экосистем для устойчивого экономического развития регионов. В русле данных исследований мы рассмат- риваем проблематику формирования стратегии развития водохозяйственного комплекса в рамках методологии, учитывающей социально-экономические и экологические аспекты регионального развития.

На первом этапе исследования анализируется влияние водохозяйственного комплекса на состояние социально-экономического потенциала региона. Данный анализ проводится в рамках концепции устойчивого развития, в соответствии с которой выделяются следующие основные аспекты:

- экономический - рациональность использования водных ресурсов в соответствии со структурно-отраслевыми особенностями регионального развития;

- социальный - уровень и качество жизни населения, выражаемые величиной расходов на услуги ЖКХ и показателями заболеваемости населения;

- экологический - соблюдение экологических норм и требований при эксплуатации водных объектов.

Показатели оценивания, используемые для проведения анализа, представлены в таблице 1.

На втором этапе исследования проводится анализ сценарных вариантов развития ВХК в отдельных регионах. Для проведения анализа были выделены признаки, характеризующие развитие регионального ВХК по каждому рассматриваемому аспекту (экономический, социальный и экологический) (см. табл. 2).

В зависимости от сочетания характеристик выделенных признаков проводится типологизация сценариев развития региональных ВХК (см. табл. 3).

Характеристика отдельных типов сценариев представлена в таблице 4.

Таблииа 1

\section{Показатели оценивания влияния ВХК на социально-экономический потенциал региона}

\begin{tabular}{|l|l|}
\hline \multicolumn{1}{|c|}{ Аспект } & \multicolumn{1}{c|}{ Показатели } \\
\hline Экономический & $\begin{array}{l}\text { Водоемкость ВРП (Объем потребления воды (свежей и оборотной) / ВРП). } \\
\text { Соотношение объемов потребления свежей воды и объемов потребления } \\
\text { оборотной и последовательно используемой воды }\end{array}$ \\
\hline Социальный & $\begin{array}{l}\text { Удельный вес потребительских расходов на услуги ЖКХ. } \\
\text { Показатели заболеваемости населения }\end{array}$ \\
\hline Экологический & Сброс загрязненных сточных вод в поверхностные водные объекты \\
\hline
\end{tabular}

Примечание. Составлено автором на основе собственных исследований. 
Характеристика признаков эффективности деятельности бассейновых упр в отношении управления региональным ВХК

\begin{tabular}{|c|c|c|}
\hline \multirow[t]{2}{*}{ Аспект } & \multicolumn{2}{|c|}{ Характеристика признака } \\
\hline & Высокий уровень & Низкий уровень \\
\hline Экономический & $\begin{array}{l}\text { Темпы роста ВРП выше темпов роста объ- } \\
\text { емов водопотребления (снижение водоем- } \\
\text { кости ВРП); увеличение удельного веса } \\
\text { оборотной и последовательно используе- } \\
\text { мой воды в общем объеме потребления } \\
\text { водных ресурсов }\end{array}$ & $\begin{array}{l}\text { Темпы роста ВРП ниже темпов роста объе- } \\
\text { мов водопотребления (рост водоемкости } \\
\text { ВРП); увеличение удельного веса свежей } \\
\text { воды в общем объеме потребления водных } \\
\text { ресурсов }\end{array}$ \\
\hline Социальный & $\begin{array}{l}\text { Удельный вес потребительских расходов на } \\
\text { услуги ЖКХ ниже среднего по России; по- } \\
\text { казатели заболеваемости населения ниже } \\
\text { среднего по России }\end{array}$ & $\begin{array}{l}\text { Удельный вес потребительских расходов на } \\
\text { услуги ЖКХ выше среднего по России; по- } \\
\text { казатели заболеваемости населения выше } \\
\text { среднего по России }\end{array}$ \\
\hline Экологический & $\begin{array}{l}\text { Снижение объемов сброса загрязненных } \\
\text { сточных вод в поверхностные водные объ- } \\
\text { екты }\end{array}$ & $\begin{array}{l}\text { Рост или неизменяющаяся динамика объе- } \\
\text { мов сброса загрязненных сточных вод в по- } \\
\text { верхностные водные объекты }\end{array}$ \\
\hline
\end{tabular}

Примечание. Составлено автором на основе собственных исследований.

Таблица 3

Типологизация политики управления ВХК в бассейновых управлениях

\begin{tabular}{|l|c|c|c|c|c|c|c|c|}
\hline \multicolumn{1}{|c|}{ Признак } & \multicolumn{9}{c|}{ Характеристика признака } \\
\hline Экономический & \multicolumn{3}{|c|}{ Высокий уровень } & \multicolumn{4}{c|}{ Низкий уровень } \\
\hline Социальный & \multicolumn{1}{|c|}{ Высокий уровень } & Низкий уровень & Высокий уровень & \multicolumn{2}{|c|}{ Низкий уровень } \\
\hline Экологический & $\begin{array}{c}\text { Высокий } \\
\text { уровень }\end{array}$ & $\begin{array}{c}\text { Низкий } \\
\text { уровень }\end{array}$ & $\begin{array}{c}\text { Высокий } \\
\text { уровень }\end{array}$ & $\begin{array}{c}\text { Низкий } \\
\text { уровень }\end{array}$ & $\begin{array}{c}\text { Высокий } \\
\text { уровень }\end{array}$ & $\begin{array}{c}\text { Низкий } \\
\text { уровень }\end{array}$ & $\begin{array}{c}\text { Высокий } \\
\text { уровень }\end{array}$ & $\begin{array}{c}\text { Низкий } \\
\text { уровень }\end{array}$ \\
\hline $\begin{array}{l}\text { Тип политики } \\
\text { управления }\end{array}$ & 1 & 2 & 3 & 4 & 5 & 6 & 7 & 8 \\
\hline
\end{tabular}

Примечание. Составлено автором.

\section{Характеристика типов сценариев развития региональных ВХК}

\begin{tabular}{|c|l|l|}
\hline $\begin{array}{c}\text { Tип } \\
\text { политики } \\
\text { управления }\end{array}$ & \multicolumn{1}{|c|}{ Характеристика признаков } & \multicolumn{1}{|c|}{ Характеристика типа сценария } \\
\hline 1 & $\begin{array}{l}\text { Высокий уровень проявления экономическо- } \\
\text { го, социального и экологического аспектов } \\
\text { деятельности }\end{array}$ & Сбалансированное развитие \\
\hline 2 & $\begin{array}{l}\text { Высокий уровень проявления экономическо- } \\
\text { го и социального аспектов деятельности, не- } \\
\text { удовлетворительная реализация экологиче- } \\
\text { ского аспекта }\end{array}$ & $\begin{array}{l}\text { Эвтрофикационное развитие, приводящее к } \\
\text { загрязнению водных экосистем }\end{array}$ \\
\hline 3 & $\begin{array}{l}\text { Высокий уровень проявления экономическо- } \\
\text { го и экологического аспектов деятельности, } \\
\text { неудовлетворительная реализация социаль- } \\
\text { ного аспекта }\end{array}$ & $\begin{array}{l}\text { Диссоциальное развитие, игнорирующее ин- } \\
\text { тересы населения в части обеспечения дос- } \\
\text { тупности качественных водных ресурсов }\end{array}$ \\
\hline 4 & $\begin{array}{l}\text { Высокий уровень проявления экономическо- } \\
\text { го аспекта деятельности, неудовлетворитель- } \\
\text { ная реализация социального и экологическо- } \\
\text { го аспектов }\end{array}$ & $\begin{array}{l}\text { Ресурсосберегающее развитие, ставящее в } \\
\text { приоритет рациональное использование вод- } \\
\text { ных ресурсов в региональном хозяйстве }\end{array}$ \\
\hline 5 & $\begin{array}{l}\text { Высокий уровень проявления социального и } \\
\text { экологического аспектов деятельности, не- } \\
\text { удовлетворительная реализация экономиче- } \\
\text { ского аспекта }\end{array}$ & $\begin{array}{l}\text { Социально ориентированное развитие, на- } \\
\text { правленное на повышение качества и доступ- } \\
\text { ности водных ресурсов при игнорировании } \\
\text { вопросов водосбережения }\end{array}$ \\
\hline
\end{tabular}

Примечание. Составлено автором. 
Окончание таблицы 4

\begin{tabular}{|c|l|l|}
\hline $\begin{array}{c}\text { Тип } \\
\text { политики } \\
\text { управления }\end{array}$ & \multicolumn{1}{|c|}{ Характеристика признаков } & \multicolumn{1}{|c|}{ Характеристика типа сценария } \\
\hline 6 & $\begin{array}{l}\text { Высокий уровень проявления социального } \\
\text { аспекта деятельности, неудовлетворительная } \\
\text { реализация экономического и экологического } \\
\text { аспектов }\end{array}$ & $\begin{array}{l}\text { Обеспечение вододоступности, ставящее в } \\
\text { приоритет обеспечение населения водными } \\
\text { ресурсами надлежащего качества при недос- } \\
\text { татке внимания проблемам водосбережения и } \\
\text { снижения ущерба окружающей среде }\end{array}$ \\
\hline 7 & $\begin{array}{l}\text { Высокий уровень проявления экологического } \\
\text { аспекта деятельности, неудовлетворительная } \\
\text { реализация социального и экономического } \\
\text { аспектов } \\
\text { оритет отдается мерам, направленным на ми- } \\
\text { нимизацию ущерба окружающей среде с не- } \\
\text { достаточным вниманием к социально-эконо- } \\
\text { мическим аспектам водопользования }\end{array}$ \\
\hline 8 & $\begin{array}{l}\text { Низкий уровень проявления всех аспектов } \\
\text { деятельности }\end{array}$ & \begin{tabular}{l} 
Неудовлетворительное развитие \\
\hline
\end{tabular} \\
\hline
\end{tabular}

На третьем этапе исследования даются рекомендации, направленные на повышение эффективности процесса стратегического управления водными ресурсами.

Объектом исследования стали регионы ЮФО, процессы управления водными ресурсами которых находятся в ведении Донского бассейнового управления (Ростовская область), Западно-Каспийского бассейнового управления (Республика Калмыкия), Кубанского бассейнового управления (Республика Адыгея, Краснодарский край), Нижневолжского бассейнового управления (Астраханская и Волгоградская области) и Крымского бассейнового управления (Республика Крым).

\section{Результаты и обсуждение}

Обеспеченность территории водными ресурсами является одним из важнейших факторов социально-экономического развития региона. Для регионов ЮФО водные ресурсы имеют особое значение в силу их сельскохозяйственной специализации при относительно большой продолжительности маловодного периода. Поверхностные воды регионов ЮФО составляют лишь 6,4 \% от общей площади [Peгионы России ..., 2020]. При этом сельскохозяйственное производство отличается высокой степенью водоемкости. Например, для выращивания 1 т зерна пшеницы необходимо 2 т воды, для выращивания 1 т риса -25 т воды. Учитывая, что в ЮФО валовой сбор зерна в 2019 г. составил 33 261,8 тыс. т, а наряду с этим в регионе выращиваются овощи, картофель, подсолнечник и другие сельскохо- зяйственные культуры, осуществляется промышленное производство, где вода используется как сырье (источник хозяйственных нужд), очевидно, что стабильное социальноэкономическое развитие региона требует огромного количества пресной воды. А эффективность функционирования ВКХ региона имеет важное значение для развития социальноэкономического потенциала региона.

Рациональность использования региональных водных ресурсов в структурно-отраслевом разрезе может быть оценена на основе анализа показателя водоемкости ВРП [Рациональность ... , 2018]. Снижение водоемкости ВРП при наличии тенденции роста последнего свидетельствует об интенсивном развитии экономики региона на основе реализации инновационных ресурсосберегающих технологий. Рост водоемкости ВРП отражает неспособность ВХК региона адаптироваться к хозяйственным нагрузкам, что свидетельствует о нерациональном водопотреблении и водопользовании.

Результаты анализа данных об уровне водоемкости ВРП в регионах ЮФО (см. рис. 1), а также данных о соотношении объемов использования свежей и оборотной и последовательно используемой воды (см. рис. 2) позволяют констатировать снижение водоемкости регионального производства. Однако несмотря на некоторое снижение удельного веса свежей воды в общем объеме ее использования, в абсолютном значении наблюдается рост данного показателя. Одновременно можно отметить, что темпы роста ВРП в ЮФО выше темпов роста объемов водопотребления, что выражается в снижении водоемкости ВРП. 
O.A. Чернова. Регионально-отраслевой подход к формированию стратегии развития ВХК

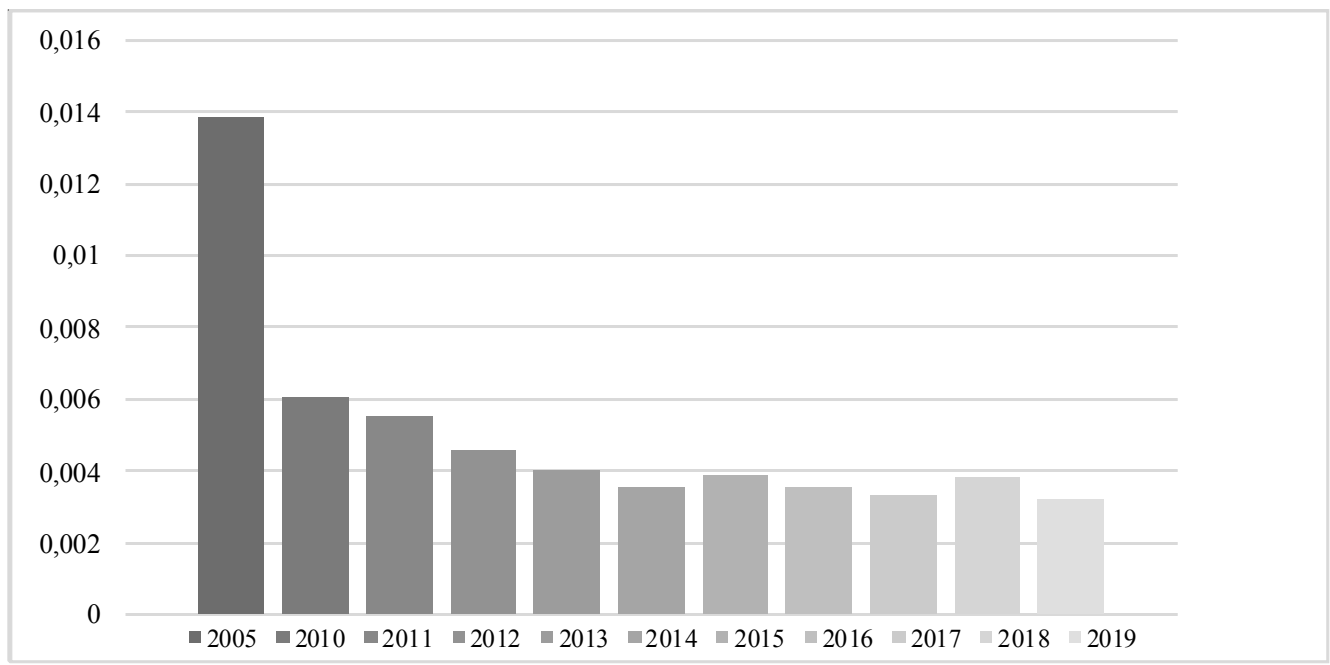

Рис. 1. Водоемкость ВРП в ЮФО, млн м³ / млн руб.

Примечание. Составлено автором по: [Регионы России ..., 2020].

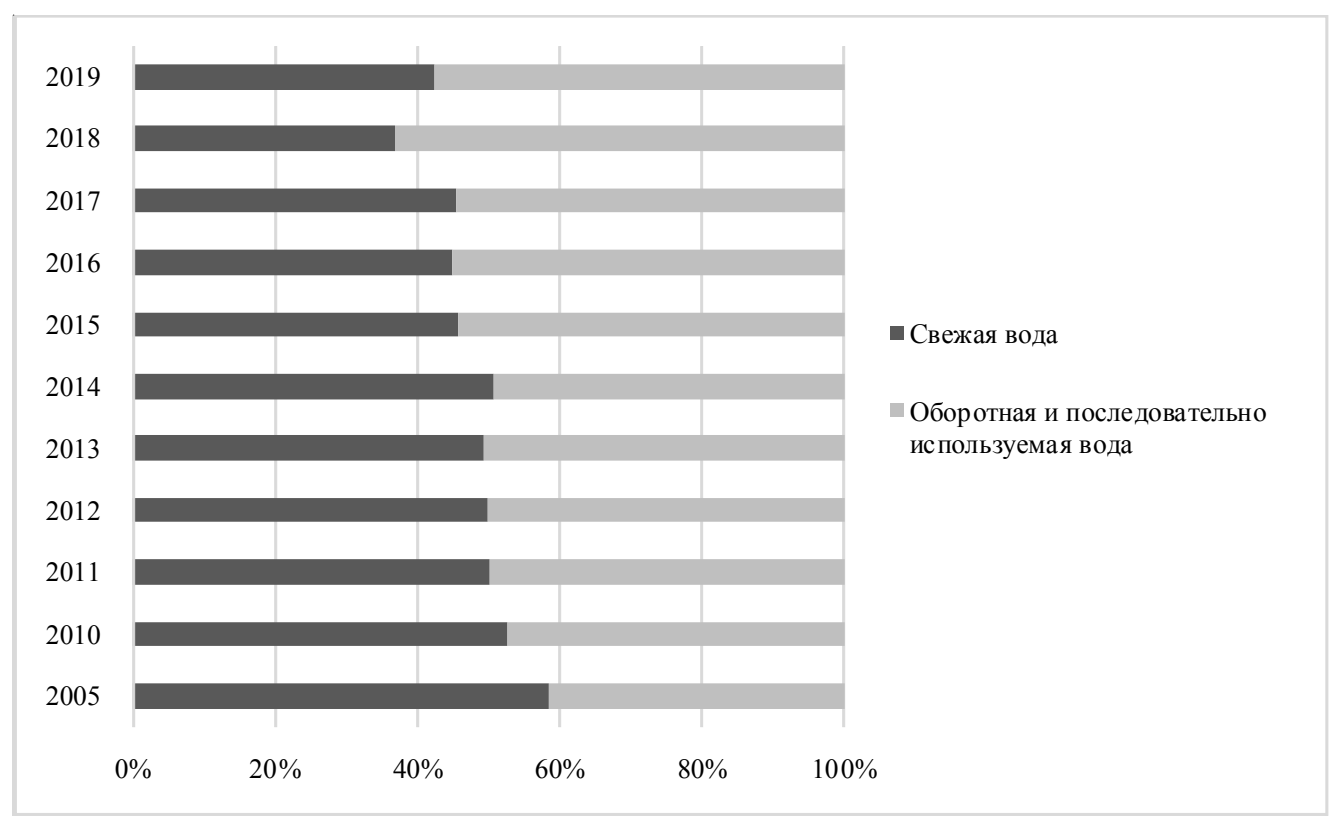

Рис. 2. Соотношение объемов использования свежей и оборотной последовательно используемой воды в ЮФО, \%

Примечание. Составлено автором по: [Регионы России ..., 2020].

Среди регионов ЮФО наибольшую водоемкость ВРП имеют Ростовская область и Республика Калмыкия. В остальных регионах данный показатель находится примерно на одинаковом уровне (см. рис. 3 ).

Одновременно следует отметить, что в структуре водопотребления в Ростовской области преобладает оборотная и последовательно используемая вода (около 75 \%). Высокий удельный вес оборотной и последовательно используемой воды в общем объеме ее потребления характерен также для Волгоградской области $(71 \%)$ и Республики Крым (51 \%). В Республике Адыгея и Республике Калмыкия преимущественно используется свежая вода (более 85 \%). Удельный вес свежей воды в общем объеме потребления воды в Краснодарском крае и Астраханской области также достаточно высок и составляет более $75 \%$.

При исследовании влияния водохозяйственного комплекса на состояние социаль- 


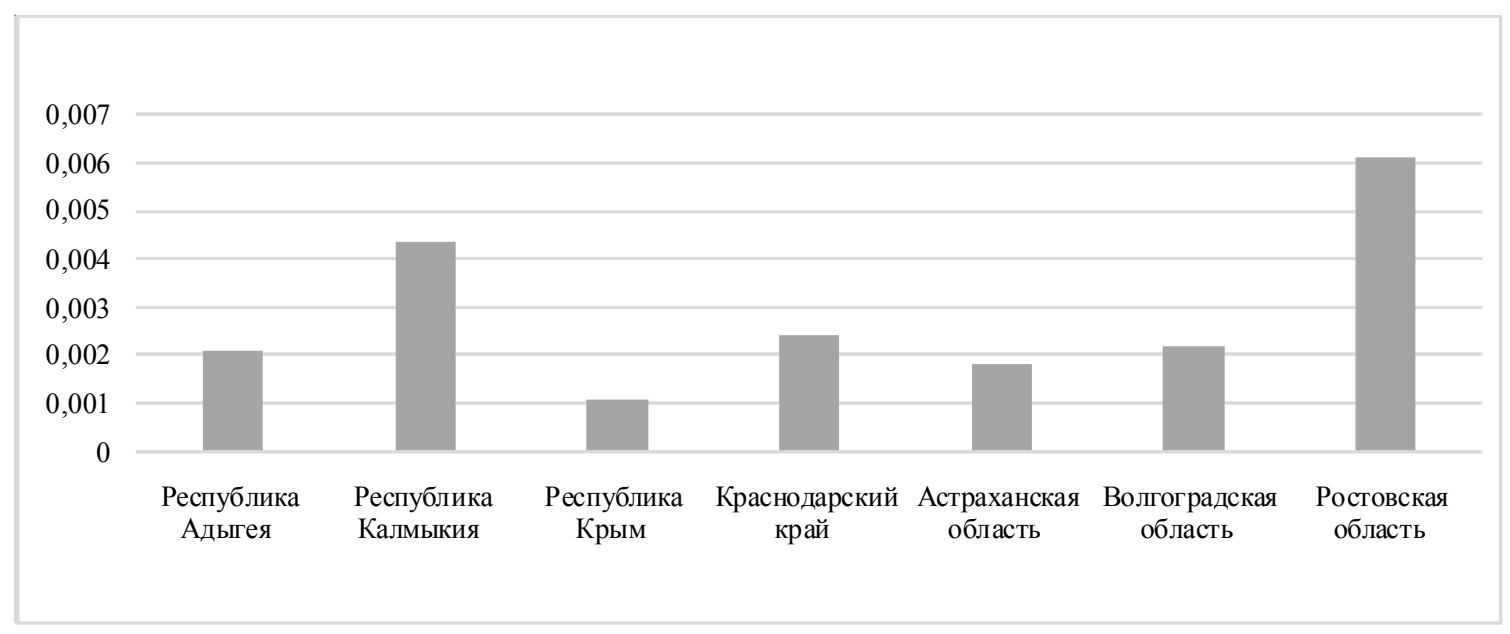

Рис. 3. Водоемкость ВРП в регионах ЮФО, млн м³ / млн руб.

Примечание. Составлено автором по: [Регионы России ... , 2020].

но-экономического потенциала региона в социальном аспекте будем учитывать удельный вес расходов населения на услуги ЖКХ в общем объеме расходов населения, а также показатели заболеваемости населения. Несмотря на то что расходы на услуги ЖКХ наряду с оплатой использования воды включают другие виды издержек, представляется возможным использовать данный показатель для оценки влияния ВХК на уровень жизни населения, поскольку водные ресурсы так или иначе являются значимым компонентом затрат в данной сфере. Что касается возможности использования показателя заболеваемости населения, то можно отметить, что результаты многочисленных исследований подтверждают, что качество питьевой воды оказывает непосредственное воздействие на здоровье граждан [Бакуменко и др., 2011; Сергеева, 2014; Роль ... , 2017; Качество ..., 2019]. А одной из важнейших задач функционирования ВХК является обеспечение населения качественной питьевой водой.

В структуре потребительских расходов удельный вес услуг ЖКХ в ЮФО в целом составляет $12 \%$, что выше среднего по России значения (10,8 \%). При этом наибольший удельный вес данных затрат характерен для Ростовской области (13\%). Для Республики Калмыкия и Астраханской области удельный вес расходов населения на услуги ЖКХ в общем объеме расходов наиболее низкий в ЮФО - 9 \%. В остальных регионах данный показатель находится на уровне 11 \%.
Что касается уровня заболеваемости населения, то в целом в ЮФО данный показатель ниже среднего по России (711,7 чел. против 780,2 чел. на 1000 населения). В разрезе регионов ЮФО наиболее высокие показатели заболеваемости (выше среднего по ЮФО) характерны для Ростовской области, Республики Калмыкия и Краснодарского края (см. рис. 4).

Оценку влияния ВКХ на экологическую составляющую социально-экономического потенциала региона проведем по показателю сброса загрязненных сточных вод в поверхностные водные объекты. Общий объем сбрасываемых сточных вод в ЮФО составляет 1239 млн м³. Основным источником загрязнений водных объектов является Краснодарский край (732 млн м³). Второе и третье места соответственно занимают Ростовская область (202 млн м $\left.{ }^{3}\right)$ и Республика Крым (113 млн м ${ }^{3}$ ). Для остальных регионов объем сбрасываемых загрязненных сточных вод составляет: Волгоградская область - 85 млн м ${ }^{3}$, Астраханская область - 36 млн м³ , Республика Адыгея 23 млн м ${ }^{3}$, Республика Калмыкия - 18 млн м². Динамика изменения показателей загрязнения водных объектов в регионах ЮФО отражена на рисунке 5 .

Характеристика приведенных показателей оценки влияния ВХК на социально-экономический потенциал региона позволяет выделить различные сценарные варианты его развития в отдельных регионах (см. табл. 5). 


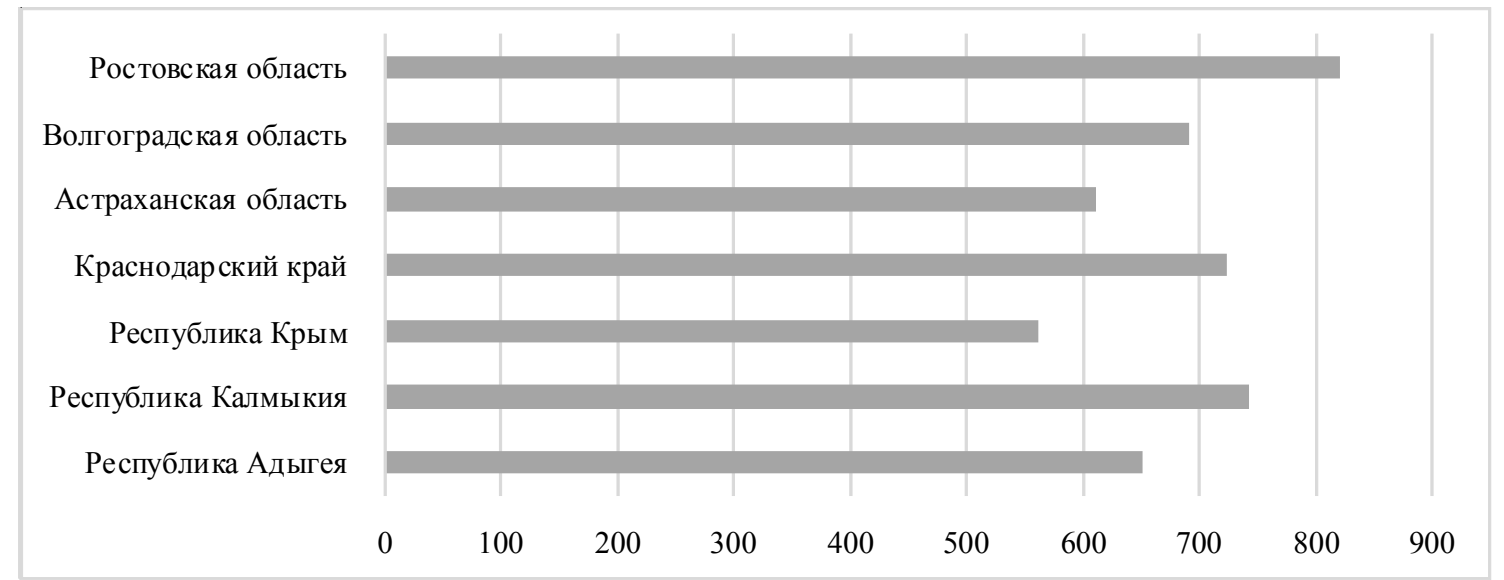

Рис. 4. Показатели заболеваемости населения на 1000 чел. населения

Примечание. Составлено автором по: [Регионы России ... , 2020].

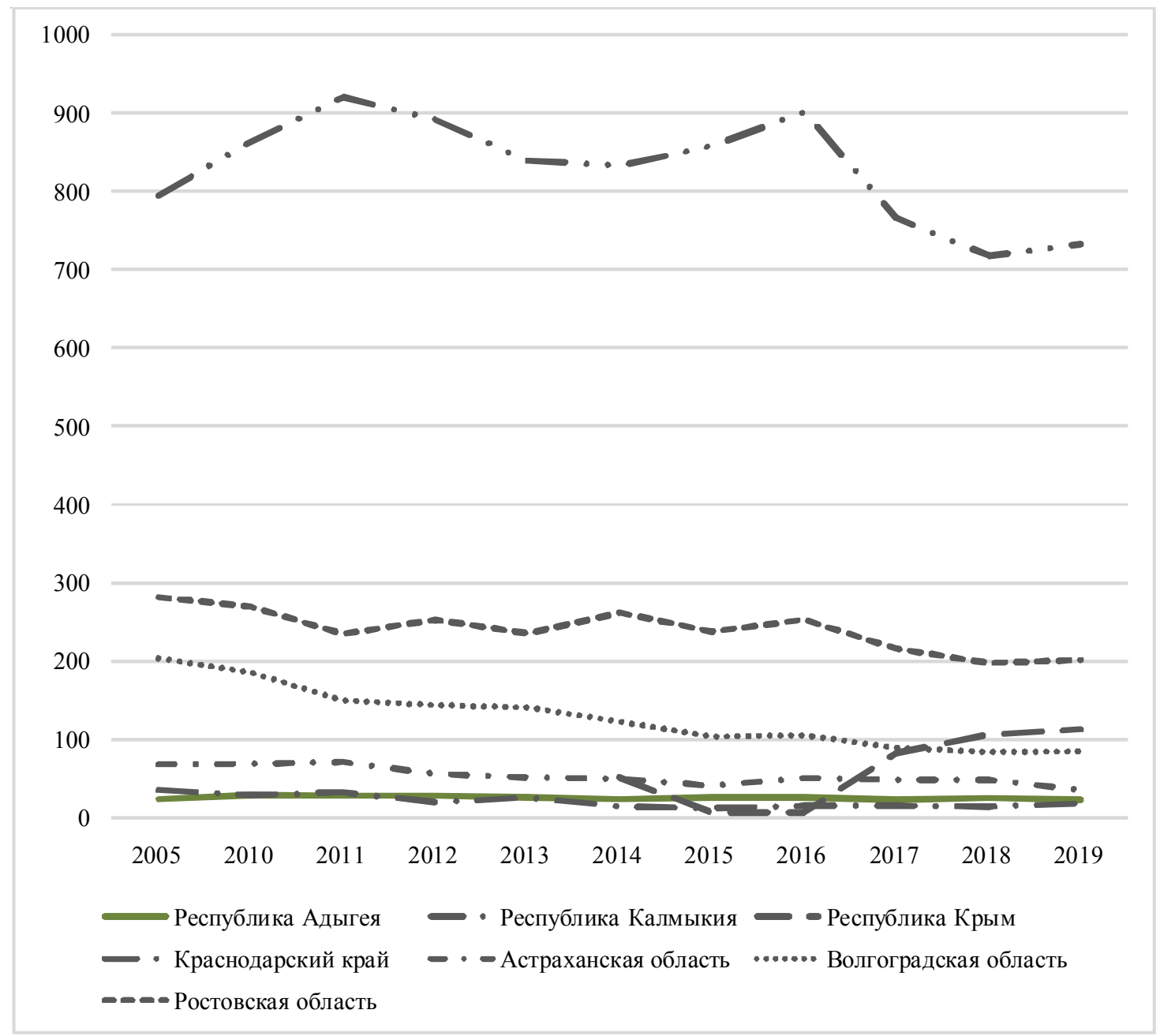

Рис. 5. Динамика изменения показателей загрязнения водных объектов в регионах ЮФО, млн м³ Примечание. Составлено автором по: [Регионы России ... , 2020]. 
Характеристика сценариев развития ВХК регионов ЮФО

\begin{tabular}{|c|c|c|c|c|c|c|c|c|}
\hline \multirow{3}{*}{$\begin{array}{l}\text { Бассейновое } \\
\text { управление }\end{array}$} & \multirow{3}{*}{ Регион } & \multicolumn{6}{|c|}{ Исследуемый аспект } & \multirow{3}{*}{ Тип сценария } \\
\hline & & \multicolumn{2}{|c|}{$\begin{array}{c}\text { Экономи- } \\
\text { ческий }\end{array}$} & \multicolumn{2}{|c|}{ Социальный } & \multicolumn{2}{|c|}{$\begin{array}{c}\text { Экологи- } \\
\text { ческий }\end{array}$} & \\
\hline & & $\begin{array}{l}\text { высо- } \\
\text { кий }\end{array}$ & $\begin{array}{l}\text { низ- } \\
\text { кий }\end{array}$ & $\begin{array}{c}\text { высо- } \\
\text { кий }\end{array}$ & $\begin{array}{l}\text { низ- } \\
\text { кий }\end{array}$ & $\begin{array}{l}\text { высо- } \\
\text { кий }\end{array}$ & $\begin{array}{l}\text { низ- } \\
\text { кий }\end{array}$ & \\
\hline \multirow[t]{2}{*}{ Кубанское БУ } & $\begin{array}{l}\text { Республика } \\
\text { Адыгея }\end{array}$ & & + & + & & & + & $\begin{array}{l}6 \text { - обеспечение вододос- } \\
\text { тупности }\end{array}$ \\
\hline & $\begin{array}{l}\text { Краснодар- } \\
\text { ский край }\end{array}$ & & + & & + & & + & $\begin{array}{l}8 \text { - неудовлетворительное } \\
\text { развитие }\end{array}$ \\
\hline $\begin{array}{l}\text { Западно-Кас- } \\
\text { пийское БУ }\end{array}$ & $\begin{array}{l}\text { Республика } \\
\text { Калмыкия } \\
\end{array}$ & & + & & + & + & & $\begin{array}{l}7 \text { - природоохранное разви- } \\
\text { тие }\end{array}$ \\
\hline Крымское БУ & $\begin{array}{l}\text { Республика } \\
\text { Крым } \\
\end{array}$ & + & & + & & & + & $\begin{array}{l}2 \text { - эвтрофикационное раз- } \\
\text { витие }\end{array}$ \\
\hline \multirow[t]{2}{*}{$\begin{array}{l}\text { Нижневолж- } \\
\text { ское БУ }\end{array}$} & $\begin{array}{l}\text { Астраханская } \\
\text { область }\end{array}$ & & + & + & & + & & $\begin{array}{l}5 \text { - социально ориентиро- } \\
\text { ванное развитие } \\
\end{array}$ \\
\hline & $\begin{array}{l}\text { Волгоград- } \\
\text { ская область }\end{array}$ & + & & + & & + & & $\begin{array}{l}1 \text { - сбалансированное раз- } \\
\text { витие }\end{array}$ \\
\hline Донское БУ & $\begin{array}{l}\text { Ростовская } \\
\text { область }\end{array}$ & + & & & + & + & & 3 - диссоциальное развитие \\
\hline
\end{tabular}

Примечание. Составлено автором.

Можно заметить значительные различия в сценариях развития ВХК в отдельных регионах. При этом отличия имеются даже для регионов, водные ресурсы которых находятся в ведении одного и того же бассейнового управления. Это свидетельствует о том, что эффективность управления водными ресурсами региона определяется не только деятельностью органов бассейнового управления, но и специфическими факторами регионального развития: отраслевая структура хозяйства, природно-климатические условия, реализуемые предприятиями бизнес-модели и пр.

Наиболее сбалансированно ВХК развивается в Волгоградской области, где наряду с реализацией мер, направленных на экономное использование водных ресурсов (в том числе на основе активного использования оборотного водообеспечения), принимаются меры по снижению уровня загрязненности водных ресурсов, а также по повышению их качества. Управление водными ресурсами в регионе осуществляется Нижневолжским БУ. Следует отметить, что в Астраханской области, водные ресурсы которой находятся в ведении этого же бассейнового управления, сценарий развития ВХК также характеризуется высокими социальными и экологическими показателями. Уровень водоемкости ВРП в регионе также довольно низкий. Однако в силу неразвитости инновационного промышленного производства Астраханская область отличается низким уровнем использования технологий оборотного и повторного водоснабжения.

Для Республики Калмыкия свойственен природоохранный сценарий развития. При этом данный регион отличается высоким уровнем водоемкости ВРП в силу специфики природно-климатических условий. Для него характерно относительно низкое качество питьевой воды.

Кубанское БУ, обеспечивающее управление водными ресурсами в Республике Адыгея и Краснодарском крае, характеризуется неэффективным распределением водных ресурсов, что отражается в низких показателях водоемкости ВРП и высоком уровне потребления свежей воды. Для данных регионов характерен рост показателей загрязненности водных ресурсов.

В Республике Крым также значительно увеличился уровень загрязненности водных ресурсов, что в определенной мере связано с интенсивным развитием в регионе хозяйственной деятельности.

В целом можно сказать, что сценарий развития ВХК региона во многом определяется содержанием региональных и отраслевых стратегий и программ, а также планов территориальной организации производства. 
Поэтому развитие ВХК должно осуществляться не исключительно в рамках бассейнового подхода к управлению, а быть дополнено регионально-отраслевым подходом.

Несмотря на то что развитие ВХК России определяется как ключевой фактор обеспечения национальной безопасности, социальной стабильности и экономического благополучия [Управление ..., 2014], единая система управления водным хозяйством отсутствует, а вопросы регулирования использования водных ресурсов находятся в ведении более 30 различных ведомств исполнительной власти. Механизм управления распределением водных ресурсов является наиболее слабым звеном в системе администрирования. Принятая в 2009 г. «Водная стратегия Российской Федерации на период до 2020 года» определила перспективы развития водного хозяйства. Однако в настоящее время ее актуализация не осуществлялась. Реализация стратегии развития ВХК осуществляется в рамках бассейнового подхода, в соответствии с которым обеспечение водными ресурсами различных региональных потребителей (население, хозяйствующие субъекты) осуществляется в соответствии с установленными нормативами без учета экономических аспектов рационального водораспределения. Рациональность водораспределения выражается в том, что оно должно быть ориентировано, во-первых, на достижение стратегических целей развития экономики региона, представленной совокупностью отраслей, совместно использующих ресурсы одного водного бассейна, во-вторых - на согласование разнонаправленных интересов потребителей водно-земельных ресурсов с учетом ограничений водохозяйственного баланса региона [The Optimization Model ..., 2020].

Другими словами, отраслевые решения должны интегрироваться в региональное стратегическое управление водными ресурсами. Наряду с этим стратегия развития ВХК региона должна учитывать и возможные сценарии изменения климата, спроса на воду, видов и форм экономической деятельности в регионе (в том числе как ответная реакция на воздействие внешних шоков пандемии).

Реализация ресурсно-отраслевого подхода к развитию ВХК региона предполагает формирование механизма межведомственной координации. Кроме того, с позиций ресурсно-отраслевого подхода при разработке стратегии развития ВХК необходимо проводить оценку воздействия результатов ее реализации на социально-экономический потенциал региона. Данная процедура предполагает необходимость привлечения общественности и всех заинтересованных сторон.

Рекомендации в отношении формирования и реализации механизма межведомственной координации в целом не являются новыми: реализация кооперативных стратегий развития хозяйствующих субъектов; развитие водохозяйственных экосистем на основе реализации циркулярных моделей экономики; ориентация на ресурсосберегающее производство; реализация инновационных технологий в системе ВХК и пр. Важное отличие от стандартных рекомендаций по повышению эффективности развития ВХК состоит в том, что речь в данном случае идет о развитии как процессе, направленном на повышение устойчивости развития ВХК как региональной экосистемы. Действия, которые традиционно реализуются для достижения устойчивости развития ВХК, не всегда тождественны тем, которые должны быть предприняты для достижения устойчивости региональной экосистемы.

\section{Выводы}

В результате проведенного исследования подтвердилась авторская гипотеза о наличии взаимосвязи и взаимообусловленности процессов стратегического развития ВХК и регионального хозяйства. Тем не менее задачи, связанные с разработкой стратегии развития ВХК, несмотря на очевидную потребность в координации и согласованиях социально-экономических, экологических, технологических и других решений, в большинстве случаев решаются в рамках бассейнового подхода к управлению водными ресурсами. Это приводит к тому, что стратегические направления развития ВХК в большинстве случаев оказываются не связанными с отраслевыми структурными преобразованиями в регионе. В стремлении к устойчивому развитию с методологической точки зрения разработка стра- 
тегии развития ВХК региона должна рассматриваться с учетом экономических, социальных и экологических аспектов ее воздействия на социально-экономический потенциал региона. Регионально-отраслевой подход к формированию стратегии развития водохозяйственного комплекса региона выражается:

- в необходимости соответствия между фактическим обеспечением водными ресурсами и отраслевой структурой экономик, а также с учетом прогнозируемых структурных изменений;

- достижении рациональности распределения водных ресурсов между региональными потребителями;

- обеспечении баланса интересов участников региональной водохозяйственной системы.

Реализация регионально-отраслевого подхода к управлению стратегическим развитием ВХК в дополнение к бассейновому будет способствовать не только решению ряда проблем, связанных с управлением водными объектами, но и комплексному устойчивому развитию водных и региональных экосистем.

\section{СПИСОК ЛИТЕРАТУРЫ}

Бакуменко, Л. П. Статистический анализ влияния качества питьевой воды на здоровье населения региона / Л. П. Бакуменко, П. А. Коротков // Прикладная эконометрика. - 2011. № 2 (22). - С. 32-47.

Качество питьевого водоснабжения и степень эпидемической опасности возникновения кишечных инфекций в городах Архангельской области // Экология человека. - 2019. - № 5. C. $15-20$.

Рациональность использования водных ресурсов в экономике горных территорий Северного Кавказа // Устойчивое развитие горных территорий. - 2018. - Т. 10, № 1 (35). - С. 48-62. DOI: 10.21177/1998-4502-2018-1-10-48-62.

Регионы России. Социально-экономические показатели. 2020 : Стат. сб. / Росстат. - М., 2020. $1242 \mathrm{c}$.

Роль санитарно-гигиенических факторов в распространении бактериальных кишечных инфекций водным путем // Здоровье населения и среда обитания. - 2017. - № 10 (295). - C. 20-23.

Сергеева, Е. С. Значение санитарно-гигиенических показателей качества воды источников водоснабжения при оценке инфекционной забо- леваемости населения / Е. С. Сергеева // Саратовский научно-медицинский журнал. 2014. - T. 10, № 3. - С. 369-372.

Управление водными ресурсами в России. Законодательное регулирование и перспективы. М. : Изд. Гос. Думы, 2014. - 192 с.

Achieve Sustainable Development of Rivers with Water Resource Management - Economic Model of River Chief System in China // Science of the Total Environment. - 2020. - Vol. 708. P. 134657.-DOI: 10.1016/j.scitotenv.2019.134657.

Achieving Win-Win Policy Outcomes for Water Resource Management and Economic Development: The Experience of Chinese Cities // Sustainable Production and Consumption. 2021. - Vol. 27. - P. 873-888. - DOI: 10.1016/ j.spc.2021.02.006.

Ahmadov, E. Water Resources Management to Achieve Sustainable Development in Azerbaijan / E. Ahmadov // Sustainable Futures. - 2020. Vol. 2. - P. 100030. - DOI: 10.1016/j.sftr.2020. 100030.

Development of a Regional Model for Integrated Management of Water Resources at the Basin Scale // Physics and Chemistry of the Earth, Parts A/B/C. - 2008. - Vol. 33, iss. 1-2. - P. 175-182.DOI: 10.1016/j.pce.2007.04.018.

Do Conservation Managers Use Scientific Evidence to Support Their Decision-Making? // Biological Conservation. - 2004. - № 119. - P. 245-252.

Integrated Planning for Regional Development Planning and Water Resources Management Under Uncertainty: A Case Study of Xining, China // Journal of Hydrology. - 2017. Vol. 554. -P. 623-634. -DOI: 10.1016/j.jhydrol. 2017.08.022

Refined Water Security Assessment for Sustainable Water Management: A Case study of 15 Key Cities in the Yangtze River Delta, China // Journal of Environmental Management. - 2021. Vol. 290. - P. 112588. - DOI: 10.1016/j.jenvman. 2021.112588.

Regionalization of Water Environmental Carrying Capacity for Supporting the Sustainable Water Resources Management and Development in China // Resources Conservation and Recycling. - 2018. - Vol. 134. - P. 282-293. DOI: $10.1016 /$ j.resconrec.2018.03.030.

The Optimization Model of the Use of Water Resources in the Agriculture of a Region Taking into Account its Specialization // Естественногуманитарные исследования. - 2020. № 31 (5). - C. 160-166. - DOI: 10.24411/23094788-2020-10542.

Tsani, S. Resource Management and Sustainable Development: A Review of the European Water 
Policies in Accordance with the United Nations' Sustainable Development Goals / S. Tsani, Ph. Koundouri, E. Akinsete // Environmental Science \& Policy. - 2020. - Vol. 114. - P. 570 579. - DOI: 10.1016/j.envsci.2020.09.00.

Water, Conflicts and Migration and the Role of Regional Diplomacy: Lake Chad, Congo Basin, and the Mbororo Pastoralist // Environmental Science \& Policy. - 2021. - Vol. 122. - P. 35-48. DOI: 10.1016/j.envsci.2021.03.019.

\section{REFERENCES}

Bakumenko L.P., Korotkov P.A. Statisticheskij analiz vliyaniya kachestva pit'evoj vody na zdorov'e naseleniya regiona [Statistical Analysis of the Influence of Drinking Water Quality on Population's Health in the Regions of Russia]. Prikladnaya ekonometrika [Applied Econometrics], 2011, no. 2(22), pp. 32-47.

Bajdakova E.V., Unguryanu T.N., Krutskaya K.V., Minenko I.A. Kachestvo pit'evogo vodosnabzheniya i stepen' epidemicheskoj opasnosti vozniknoveniya kishechnyh infekcij v gorodah Arhangel'skoj oblasti [Quality of Drinking Water and Epidemic Risk of Infections in Towns of the Arkhangelsk Region]. Ekologiya cheloveka [Human Ecology], 2019, no. 5, pp. 15-20.

Kosolapov A.E., Kosolapova N.A., Matveeva L.G., Chernova O.A. Racional'nost' ispol'zovaniya vodnyh resursov v ekonomike gornyh territorij Severnogo Kavkaza [Efficiency of Water Resource Use in Economics of the North Caucasus Mountain Territories]. Ustojchivoe razvitie gornyh territorij [Sustainable Development of Mountain Territories], 2018, vol. 10, no. 1 (35), pp. 48-62. DOI: $10.21177 / 1998$ 4502-2018-1-10-48-62.

Regiony Rossii. Social'no-ekonomicheskie pokazateli. 2020: Stat. sb. [Regions of Russia. Socio-Economic Indicators. 2020: Statistical Collection]. Moscow, 2020. 1242 p.

Aleshnya V.V., Zhuravlyov P.V., Panasovec O.P., Artyomova T.Z., Zagajnova A.V., Shvager M.M., GluhovA.A., Dzhansejidov B.H., Murachyova N.N. Rol' sanitarno-gigienicheskih faktorov $\mathrm{v}$ rasprostranenii bakterial'nyh kishechnyh infekcij vodnym putem [The Role of Sanitary and Hygienic Factors in the Spread of Bacterial Intestinal Infections by Water]. Zdorov'e naseleniya i sreda obitaniya [Public Health and Life Environment], 2017, no. 10 (295), pp. 20-23.

Sergeeva E.S. Znachenie sanitarno-gigienicheskih pokazatelej kachestva vody istochnikov vodosnabzheniya pri ocenke infekcionnoj zabolevaemosti naseleniya [Significance of the Sanitary-Hygienic Indicators of the Water Source Quality for the Assessment of the Morbidity of Infectious Diseases]. Saratovskij nauchnomedicinskij zhurnal [Saratov Journal of Medical ScientificResearch], 2014, vol. 10, no. 3, pp. 369-372. Upravlenie vodnymi resursami v Rossii. Zakonodatel'noe regulirovanie i perspektivy [Water Resources Management in Russia. Legislative Regulation and Prospects]. Moscow, Izdanie Gosudarstvennoy Dumy, 2014. 192 p.

Liu X., Pan Y., Zhang W, Ying L., Huang W. Achieve Sustainable Development of Rivers with Water Resource Management - Economic Model of River Chief System in China. Science of the Total Environment, 2020, vol. 708, p. 134657. DOI: 10.1016/j.scitotenv.2019.134657.

Yang T., Zhu Y., Li Y., Zhou B. Achieving Win-Win Policy Outcomes for Water Resource Management and Economic Development: The Experience of Chinese Cities. Sustainable Production and Consumption, 2021, vol. 27, pp. 873-888. DOI: 10.1016/j.spc.2021.02.006.

Ahmadov E. Water Resources Management to Achieve Sustainable Development in Azerbaijan. Sustainable Futures, 2020, vol. 2, p. 100030. DOI: 10.1016/j.sftr.2020.100030.

Gaiser T., PrintzA., Schwarzvon Raumer H.G, Götzinger J., Dukhovny V.A., Barthel R., Sorokin A., Tuchin A., Kiourtsidis C., Ganoulis I., Stahr K. Development of a Regional Model for Integrated Management of Water Resources at the Basin Scale. Physics and Chemistry of the Earth, Parts $A / B / C, 2008$, vol. 33, iss. 1-2, pp. 175-182. DOI: 10.1016/j.pce. 2007.04.018.

Pullin A.S., Knight T.M., Stone D.A., Charman K. Do Conservation Managers Use Scientific Evidence to Support Their Decision-Making? Biological Conservation, 2004, no. 119, pp. 245-252.

Fu Z.H., Zhao H.J., Wang H., Lu W.T., Wang J., Guo H.C. Integrated Planning for Regional Development Planning and Water Resources Management Under Uncertainty: A Case Study of Xining, China. Journal of Hydrology, 2017, vol. 554, pp. 623-634. DOI: 10.1016/j.jhydrol.2017.08.022.

Dou P., Zuo Sh., Ren Y., Rodriguez M., Dai Sh. Refined Water Security Assessment for Sustainable Water Management: A Case Study of 15 Key Cities in the Yangtze River Delta, China. Journal of Environmental Management, 2021, vol. 290, p. 112588. DOI: 10.1016/j.jenvman.2021.112588.

Jia Z., Cai Y., Chen Y., Zeng W. Regionalization of Water Environmental Carrying Capacity for Supporting the Sustainable Water Resources Management and Development in China. Resources 
Conservation and Recycling, 2018, vol. 134, pp. 282-293. DOI: 10.1016/j.resconrec.2018.03.030.

Matveeva L.G., Chernova O.A., Kosolapova N.A., Lihackaya E.A. The Optimization Model of the Use of Water Resources in the Agriculture of a Region Taking into Account Its Specialization. Estestvenno-gumanitarnye issledovaniya [Natural Sciences and Humanities Research], 2020, no. 31 (5), pp. 160-166. DOI: 10.24411/23094788-2020-10542.

Tsani S., Koundouri Ph., Akinsete E. Resource Management and Sustainable Development:
A Review of the European Water Policies in Accordance with the United Nations' Sustainable Development Goals. Environmental Science \& Policy, 2020. vol. 114, pp. 570-579. DOI: 10.1016/j.envsci.2020.09.00.

Nagabhatla N., Cassidy-Neumiller M., Francine N., Maatta N. Water, Conflicts and Migration and the Role of Regional Diplomacy: Lake Chad, Congo Basin, and the Mbororo Pastoralist. Environmental Science \& Policy, 2021, vol. 122, pp. 35-48. DOI: 10.1016/j.envsci. 2021.03.019.

\section{Information About the Author}

Olga A. Chernova, Doctor of Sciences (Economics), Associate Professor, Professor, Department of Information Economics, Southern Federal University, Gorkogo St, 88, 344002 Rostov-on-Don, Russian Federation; Leading Researcher, Russian Information, Analytical and Scientific Research Water Management Center, Filimonovskaya St, 174, 344000 Rostov-on-Don, Russian Federation, chernova.olga71@yandex.ru, https://orcid.org/0000-0001-5072-7070

\section{Информация об авторе}

Ольга Анатольевна Чернова, доктор экономических наук, доцент, профессор кафедры информационной экономики, Южный федеральный университет, ул. Горького, 88, 344002 г. Ростов-наДону, Российская Федерация; ведущий научный сотрудник, Российский информационно-аналитический и научно-исследовательский водохозяйственный центр, ул. Филимоновская, 174, 344000 г. Ростовна-Дону, Российская Федерация, chernova.olga71@yandex.ru, https://orcid.org/0000-0001-5072-7070 